\title{
UN MUNDO APOLAR: ANÁRQUICO Y VIOLENTO
}

\author{
AN APOLAR WORLD: ANARCHIC AND VIOLENT
}

Oswaldo de Rivero Barreto *

\section{RESUMEN}

El presente artículo fundamenta la estructura apolar del mundo actual en que vivimos, con una anarquía agravada por la pandemia del COVID-19, así como por los efectos del calentamiento global. Asimismo, el autor nos plantea cuatro propuestas para hacer frente a la crisis sanitaria, así como el realismo con el que el Perú debe dirigir su política exterior.

Palabras clave: mundo apolar, anarquía, armas nucleares, Covid-19, pandemia, calentamiento global, Estados Unidos de América, China, Rusia, Brasil, realismo político.

\section{ABSTRACT}

This article supports the apolar structure of the current world in which we live, with anarchy aggravated by the COVID-19 pandemic, as well as by the effects of global warming. Likewise, the author presents four proposals to face the health crisis, as well as the realism with which Peru must direct its foreign policy.

Keywords: apolar world, anarchy, nuclear weapons, Covid-19, pandemic, global warming, United States of America, China, Russia, Brazil, political realism.

\footnotetext{
* Embajador del Servicio Diplomático de la República. Se desempeñó como Representante Permanente ante las Naciones Unidas en la ciudad de Nueva York, Embajador de Perú ante la Organización Mundial del Comercio, entre otros importantes cargos en Londres, Moscú y Ginebra. Estudió derecho en la Universidad Católica (Lima) y luego obtuvo una maestría en relaciones internacionales en la Academia Diplomática de Perú. Realizó estudios de posgrado en el Graduate Institute of International Studies (Ginebra). Es autor de libros sobre desarrollo internacional, que han sido traducidos a varios idiomas.

Este artículo es un extracto de la tercera edición en inglés del libro de Oswaldo de Rivero Barreto: The Myth of Development and The Crisis de Civilization", publicado por Zed Books en Londres y Macmillan Press en Nueva York.

Con el presente artículo, el autor formaliza su incorporación como Miembro Asociado, conforme a lo dispuesto por el Consejo Directivo de la Sociedad Peruana de Derecho Internacional, mediante Acta del 13 de diciembre de 2018.
} 
El derrumbe de la Unión Soviética cambió el poder mundial de bipolar a unipolar, convirtiendo a los EEUU en el hegemón mundial, hasta que las guerras asimétricas de Afganistán, Irak y Siria, terminaron con el poder unipolar norteamericano, originando una nueva era geopolítica, que yo he llamado "apolar," donde los EEUU no son más el sheriff del mundo, y Rusia y China, no pueden ni quieren reemplazarlo.

En este mundo apolar, los arsenales nucleares de los Estados Unidos, Rusia y China han perdido su sentido estratégico, debido a que los conflictos alimentados por odios étnicos históricos y mesianismos religiosos, no se resuelven con disuasión nuclear. Tampoco, ninguna gran potencia puede hoy sola poner orden en el mundo con sus armas convencionales, so pena de involucrarse en interminables guerras asimétricas. Vivimos así una crisis del poder mundial.

Entre los conflictos más infernales están la Yihad islámica terrorista contra Occidente, la fanática lucha de los Talibanes contra todo progreso social y la guerra sectaria entre chiitas y Sunnís en los países árabes, de la cual surgió el monstruoso Estado Islámico.

La anarquía del mundo apolar también se manifiesta por la indolencia de las grandes potencias industriales frente al imparable recalentamiento del planeta que ellas han causado y siguen causando con sus emisiones de gases efecto invernadero. También, esta anarquía se muestra ahora, más que nunca, por su falta de cooperación entre las grandes potencias, como EEUU, China y Rusia, para cooperar y lograr un plan global de lucha contra la letal pandemia COVID-19.

La anarquía y la violencia de este mundo apolar, solo podría superarse en gran parte, si los EEUU, Rusia y China se ponen de acuerdo para luchar contra el terrorismo islámico, la proliferación de las armas nucleares, el cambio climático y la actual pandemia COVID-19, que son las cuatro grandes amenazas que confronta hoy la humanidad. Sin embargo, hasta ahora esto es imposible porque los EEUU están enfrascados en una peligrosa confrontación geopolítica con Rusia y China, a la vez.

\section{Unir para no reinar}

La actual confrontación entre los EEUU y Rusia tiene su origen en el no cumplimiento del acuerdo geopolítico más importante de la post guerra fría, como fue la reunificación de Alemania. En este acuerdo, Rusia dio su beneplácito a la reunificación alemana a condición de que los EEUU no extendieran la OTAN hacia Europa del Este. Los EEUU violaron este compromiso. La OTAN, no solo reclutó a casi todos los países del Este de Europa, sino que intentó reclutar a Ucrania, una zona importante de influencia geopolítica histórica de Rusia, donde inclusive vive población rusa. El resultado de esta ambición, de los EEUU y la OTAN, ha sido el estallido de un conflicto armado en Ucrania, que hasta ahora no tiene solución.

Lo que no tiene explicación estratégica, es cómo los EEUU teniendo a Rusia de nuevo como rival mundial militar, se ha lanzado a confrontar a China. No la reconoce como gran potencia y la confronta con una guerra comercial y un desdén geopolítico peligroso, que consiste en 
no reconocer que China considera el llamado Mar del Sur de la China como su zona de influencia.

Esta confrontación geopolítica simultánea con Rusia y China es un gran error estratégico de los EEUU. Es el abandono de más de 40 años de la política exterior de Kissinger, frente a Rusia y China, que funcionaba bajo el dictum de "dividir para reinar." Ahora, los EEUU, con su confrontación simultánea a Rusia y China, han cambiado esta política bajo el dictum surrealista, de "unir para no reinar". En efecto, gracias a los EEUU, Rusia y China son hoy aliados estratégicos.

\section{Más armas nucleares y más recalentamiento global}

Hoy son nueve los países que poseen el arma nuclear. A las cinco grandes potencias nucleares, los EEUU, Rusia, China, Reino Unido y Francia, se han sumado, Israel, India, Pakistán y Corea del Norte. Y lo más peligroso de esta proliferación es que la anarquía apolar ha permitido que un régimen pobre y paranoico como Corea del Norte y un Estado inviable, rodeado de fanáticos talibanes, como Pakistán, se doten de armas nucleares.

Encima de esto, los EEUU y Rusia se han lanzado a modernizar sus arsenales nucleares con una nueva generación de estas armas, abandonando peligrosamente el control mutuo de los armamentos nucleares que existían en la guerra fría entre EEUU y la Unión Soviética.

Por otro lado, la anarquía apolar se manifiesta porque ninguna de las grandes potencias industriales está hoy reduciendo suficientemente sus emisiones de $\mathrm{CO} 2$, para llegar a la meta, recomendada por los científicos, de reducirlas en un 45\% para el año el 2030. Sin duda, esta actitud se debe a que el Acuerdo de Paris, por más que se le glorifique, es un acuerdo muy débil, porque dispone que las reducciones de las emisiones de CO2 se hagan como una contribución voluntaria y no como una obligación jurídica.

El hecho que las potencias industriales no reduzcan sus emisiones de $\mathrm{CO} 2$, como lo recomiendan los científicos, están haciendo imparable el recalentamiento de nuestro planeta. Hoy, los huracanes, las inundaciones, las sequías y los incendios forestales son más intensos. También se están deshielando aceleradamente Groenlandia, el Ártico y la Antártida, lo cual va alzar peligrosamente los océanos.

Ante esta situación, muchos ecologistas han declarado que nuestro planeta está en crisis. Esto no es cierto. La Tierra no está en ninguna crisis cosmológica, sigue dando vueltas alrededor del Sol sin problemas. Lo que sí está en crisis es nuestra civilización urbana global, que no cesa de vomitar a la atmosfera gases $\mathrm{CO} 2$ que están recalentando el planeta peligrosamente. El mal llamado homo sapiens, está convirtiendo el clima del planeta en una amenaza a su propia existencia. Nuestra especie se está comportando con la misma lógica de una célula cancerosa, que destruye el cuerpo del cual vive. Si seguimos destruyendo el medio ambiente, que nos hace vivir, llegará el día en que el planeta seguirá dando vueltas alrededor del Sol, pero lo hará sin nosotros. 


\section{Sudamérica: bienvenidos a la disuasión}

También, Sudamérica está afectada por la anarquía apolar. Hoy existe una carrera armamentista iniciada en el año 2008 por Chile, adquiriendo aviones de combate F16, tanques Leopardo, modernos submarinos y fragatas. Todas armas ofensivas. Y recientemente, a pesar de la profunda crisis social, Chile acaba de adquirir dos fragatas de la marina australiana. A esta carrera armamentista se unieron más tarde Brasil y Venezuela con masivas compras de armas. Colombia también comenzó a modernizar su defensa nacional y Ecuador adquirió tanques Leopardo. El Perú no pudo quedarse atrás, ante la presencia de modernas armas ofensivas chilenas cerca de su frontera, y también comenzó la modernización de sus fuerzas armadas. Lo caótico y grave de este armamentismo chileno es que coincide con el surrealista triángulo terrestre inventado por Chile, que no es otra cosa, que una revisión del Tratado de Paz y Límites de 1929.

Ante la carrera armamentista en Sudamérica, que no inició el Perú, debemos superar esa candorosa percepción idealista, muy peruana, que consiste en pensar que adquirir o fabricar armamentos es un gasto inmoral inútil, ya que la paz es hija del desarme, inclusive del suicida desarme unilateral, que alguna vez practicaron ineptos dirigentes del Perú.

Esta percepción pacifista de no querer tener capacidad de disuasión, es la mejor invitación al conflicto armado. Además, no tiene ningún valor, porque el desarme nunca se ha logrado pacíficamente en ninguna región del planeta, y menos aún se va a lograr ahora, en un mundo apolar, que se volverá más anárquico, caótico y violento con las profundas crisis sociales que surgen en todas las regiones del mundo como resultado de la pandemia COVID-19. Además, a estas graves crisis sociales hay que añadir la escasez de agua, alimentos y energía que está ya causando en Sudamérica y en el mundo el cambio climático. Todo esto hará que muchos de los conflictos internos e internacionales, que se creían imposibles se vuelvan probables. Entonces, si el Perú quiere vivir en paz, debe seguir modernizando sus fuerzas armadas hasta lograr "un poder de disuasión creíble."

\section{La pandemia y el orden apolar anárquico y violento}

La pandemia COVID-19 no ha cambiado este orden apolar, caótico y violento en que vivimos. Muchos analistas tenían la esperanza que los EEUU, China y Rusia, dejando de lado sus rivalidades geopolíticas, se unieran ante una plaga que afecta a toda la humanidad, y comenzaran así una estrecha cooperación, para establecer una lucha común frente al virus COVID-19. Esto no ha sucedido, al contrario, el virus ha sido tratado nacionalmente con modelos distintos. Y no solo esto, sino que la administración Trump ha acusado a China de demorar el anuncio de la aparición del virus en su territorio.

Posiblemente, el gobierno chino demoró en anunciar la pandemia para no crear pánico y con ello perder el control, que el partido comunista ejerce sobre el pueblo chino. Sin embargo, esto no afectó a los EEUU, pues la CIA, el Departamento de Estado y el Centro de Control y Prevención de Enfermedades (CDC) informaron, con mucha anticipación, al presidente Trump, que en China había surgido el Covid-19. La respuesta de Trump, para no dañar su 
reelección, fue quitarle importancia a la pandemia, diciendo que era "una farsa china" y que los "EEUU era el país mejor preparado del mundo para enfrentar cualquier pandemia.

El presidente Trump sigue ahora atacando a China con el objeto que el electorado estadounidense se olvide que los EEUU son el país del mundo con más infectados y más muertes, como producto de la incompetencia de la administración Trump.

Esta incompetencia del gobierno de Washington frente a la pandemia, ha convertido a la Casa Blanca en una suerte de Pirámide Maya, que pide cada vez más sacrificios humanos. Los muertos por la caótica política del presidente Trump suman hoy cerca de 100 mil. Y según un estudio de la universidad de Washington, el insensato plan de la administración Trump de abrir totalmente la gran economía norteamericana, sin ningún estudio científico previo, produciría 3 mil sacrificios humanos diarios, haciendo que los muertos en los EEUU lleguen a más de un millón.

La realidad es que los EEUU son hoy la potencia mundial más desacreditada en la lucha contra la pandemia. El virus COVID-19, no solo ha confirmado que los EEUU no es más el Sheriff del mundo, sino que carece de gobernabilidad nacional para enfrenta una amenaza global. Además, la pandemia ha revelado la gran desigualdad social de los EEUU. El 70\% de los estadounidenses fallecidos son gente pobre. La pobreza en los EEUU, alcanza hoy a 40 millones de personas, de ellas 28 millones no tienen seguro médico. Son así parias a la merced del virus.

También, la pandemia ha demostrado la quiebra ideológica del capitalismo financiero norteamericano, frente su mayor rival, el capitalismo de manufacturero chino. En efecto, el capitalismo financiero norteamericano fue incapaz de producir suficientes ventiladores, no porque no tenía la tecnología, sino porque la mayoría de las piezas de los ventiladores son fabricadas por el capitalismo manufacturero chino. Esto obligó a los EEUU a importar de China los ventiladores, lo que demoró su uso hasta convertir en el país con más mortalidad en el mundo.

Con la recesión de todas las economías nacionales y de la económica global, como consecuencia de la pandemia, será muy difícil salir del caos y la violencia que produce el vacío de poder mundial del actual mundo apolar. La pandemia ya está creando empobrecimiento y descontento social global. La gente por todo el mundo quiere volver a trabajar, quiere vivir una vida normal y los políticos van cediendo ante esta presión que es comprensible, pero que, en la mayoría de los casos, no tiene base científica. Y así las medidas de contención de la pandemia, como la cuarentena, la distancia social, las pruebas y el rastreo de los infectados, que son científicamente necesarios, para bajar la alta tasa de mortalidad, se van relajando bajo la presión popular.

Esta tendencia de abrir la economía sin parámetros científicos va hacer que la pandemia rebrote con fuerza, convirtiendo a muchos gobiernos, como ha pasado con la Casa Blanca, en una suerte de Pirámides Mayas, que producirán miles de sacrificios humanos para calmar a la diosa economía. 
Según eminentes epidemiólogos y la OMS, a partir de setiembre, habrá de nuevo altas cifras de hospitalización y mortalidad. Entonces, si prevalece una apertura económica no científica, el mundo tendría que adaptarse a esta nueva terrible normalidad, de vivir produciendo sacrificios humanos para mantener la actividad económica.

Ante esta horrible nueva normalidad preparé una propuesta para que el Perú promueva en la Organización Mundial de la Salud (OMS) una Reunión de Científicos (los epidemiólogos más prestigiados del mundo) para que tomen cuatro medidas urgentes:

1. Establecer las precondiciones científicas que permitan la apertura gradual de las economías nacionales sin crear más muertes.

2. Dar a conocer y recomendar los tratamientos exitosos que han servido para mitigar la pandemia, bajando sus tasas de mortalidad. Los científicos trasmitirían al mundo entero las terapias que están salvando vidas.

3. Ponerse de acuerdo para obtener una vacuna lo más pronto posible e informando a todos los países en qué estado está la investigación de la vacuna, qué laboratorios investigan y qué hay que hacer para tenerla lo más pronto posible.

4. Declarar que la vacuna no sea la propiedad intelectual de ningún laboratorio del mundo, sino un "patrimonio común de toda la humanidad" accesible a muy bajos costos para todos los países.

Esta última medida, se ha fortalecido debido a que el presidente Xi de la China, en su mensaje a la Asamblea de la OMS, coincidió con la cuarta medida, diciendo que la vacuna debería ser "un bien público de toda la humanidad".

Estas son las cuatro medidas que nos pueden salvar de una horrible nueva normalidad, como sería convivir con aperturas económicas aceptando como normal una tasa alta de mortalidad. En otras palabras, estaríamos volviendo en el siglo XXI a los sacrificios humanos.

El mundo pide a gritos más ciencia y menos política en el trato de esta gran tragedia humana global. Fue esta necesidad la que me llevó a enviar al Canciller, mi propuesta de que el Perú le pida a la OMS la convocación de una Reunión de Científicos (los más inminentes epidemiólogos del mundo) para organizar un plan global de lucha contra la pandemia con la contribución de estos cuatro puntos del Perú y otras propuestas que presenten los científicos convocados por la OMS.

\section{Realpolitik}

En este mundo apolar, anárquico y violento, solo se adaptan y sobreviven los países que saben luchar por sus intereses nacionales con realismo. El Perú por ello debe practicar una política internacional descarnadamente realista, totalmente desprovista de percepciones ideológicas, solo guiada por nuestro interés nacional. Esta realpolitik tiene que tener como objetivo lograr una "renta estratégica" que incremente nuestro poder de negociación internacional. 
Para ello, debemos fortalecer nuestras relaciones con los EEUU y también las alianzas estratégicas que tenemos con Rusia y China, y sobre todo, la que tenemos con nuestro vecino Brasil, independiente esto de la ideología del actual régimen, porque las ideologías de los gobernantes pasan y los interese nacionales son permanentes.

Un interés nacional urgente, que tenemos que hacer realidad, es que las alianzas estratégicas del Perú con el Brasil y del Perú con China, aterricen, haciendo que el comercio entre ambas potencias por el Pacifico se haga a través de puertos peruanos. Lograr que el Perú sea la conexión comercial, entre el Brasil, que es la primera potencia latinoamericana, y China, que es la nueva potencia mundial, nos dará una renta estratégica geopolítica regional y mundial.

Hoy, la carga comercial del Brasil a China tiene que navegar hasta el Canal de Pananá para entrar al Pacífico y de allí navegar hasta California, para ser trasladada, en los puertos de Los Ángeles y Long Beach, hacia China. Este largo y caro viaje se superaría si el Perú y Brasil lograr poner en marcha el proyecto chino del ferrocarril de Santos, a Ilo. También, la carga del Brasil podrá salir además por el nuevo puerto de Chancay que pronto se va construir con capitales chinos, y que estos usan llamar: la conexión Chancay-Shanghái.

Otro gran interés nacional urgente, es que el Perú no se vuelva un estado nación inviable, debido a la grandiosa crisis de agua, nunca vista en nuestra historia, que ya está produciendo el cambio climático con el deshielo acelerado de los glaciares de los Andes. Ante esta amenaza existencial del Perú, nuestra diplomacia debe ayudar a localizar las mejores tecnologías, para desalinizar el agua de mar con energía solar. Y además, promover la cooperación del estado y empresas peruanas con firmas extranjeras para lograr una gran inversión en energía solar, que abunda en nuestra costa. Ya es tiempo de comenzar a vivir con el "Sol del Perú", puesto que con la sequía de los ríos de la costa nuestra producción de alimentos y nuestra energía hidroeléctrica tiene los años contados con el deshielo de los glaciares, Los científicos consideran que a partir del 2030 el acceso al agua en los países andinos será ya extremadamente crítico. Según los analistas políticos esta carestía crítica del agua, producirá serias turbulencias sociopolíticas en la región andina desde Colombia hasta la Patagonia. Sin duda, con el derretimiento de los glaciares de los Andes se derretirá también la gobernabilidad en los países andinos.

Respecto a la pandemia ha surgido un nuevo interés nacional, que no es solo peruano sino de la humanidad, como es que la pandemia no se politice en la OMS, con los pleitos en su seno, entre los EEUU, China, Australia y otros países, en torno a una investigación a China, sobre su responsabilidad por el COVID-19. Para lograr la despolitización de la OMS, el Perú debe pedir que esta organización convoque una Reunión de Científicos para crear un plan global para tratar la Pandemia. 